\title{
Green tea extract-mediated augmentation of imipenem antibacterial activity against Enterobacter cloacae clinical isolates
}

\author{
Rezky Yanuarti ${ }^{1,2}$, Firzan Nainu $^{3}$, Sartini* 3 \\ ${ }^{1}$ Magister Program Faculty of Pharmacy, Hasanuddin University \\ Jl. Perintis Kemerdekaan km. 10, Tamalanrea, Makassar, South Sulawesi, Indonesia \\ ${ }^{2}$ Sekolah Tinggi Ilmu Farmasi Palu \\ Jl. Wolter Monginsidi No.106 A, Lolu Sel., Palu, Central Sulawesi, Indonesia \\ ${ }^{3}$ Faculty of Pharmacy, Hasanuddin University \\ Jl. Perintis Kemerdekaan km. 10, Tamalanrea, Makassar, South Sulawesi, Indonesia
}

Submitted: 16-09-2020

Reviewed: 22-01-2021

Accepted: 24-03-2021

\begin{abstract}
The emergence of pathogenic bacteria with $\beta$-lactam antibiotics-resistant profile has threatened the continued use of such antibiotics in the future. This research was conducted to investigate the antimicrobial activity of green tea ethanol extract (GTE) and its ability to improve the antibacterial action of several $\beta$-lactam antibiotics against Enterobacter cloacae clinical isolates. The simplicia of green tea was extracted by sonication for 30 minutes using $50 \%$ ethanol solvent, and the total phenolic content of the GTE was subsequently determined. Next, the GTE used in testing against two clinical isolates of E. cloacae was obtained from the Pathology Laboratory of Wahidin Sudiro Husodo Hospital in Makassar. The sensitivity of bacteria to GTE was confirmed using the agar diffusion method, the Vitek ${ }^{\circledR}$ rapid method, and the double-disk synergistic test. Antibacterial activity of antibiotics, GTE, and combination of antibiotics with GTE were then tested against clinical isolates of E. cloacae using the checkerboard microdilution assay. The results showed that GTE contained $51.64 \pm 0.21 \%$ measured as gallic acid equivalent and $37.95+5.17 \%$ Epigallocatechin gallate (EGCG). The confirmatory test results indicated that one clinical isolate of $E$. cloacae (code 13/04) was resistant to amoxicillin-clavulanate but did not produce an extended-spectrum $\beta$-lactamase (ESBL). Another clinical E. cloacae isolate (code $275 \mathrm{~B} / 06$ ) was indicated to produce ESBL and demonstrated to yield resistance to amoxicillinclavulanate and cefotaxime. The minimum inhibitory concentration of GTE against the two clinical isolates of E. cloacae was $>8000 \mathrm{ppm}(8 \mathrm{mg} / \mathrm{ml})$. In conclusion, GTE could not increase the antibacterial activity of amoxicillin and cefotaxime, but it was sufficient to improve the activity of imipenem against the tested isolates of E. cloacae.
\end{abstract}

Keywords: $\beta$-lactam antibiotics, Camellia sinensis L., Antibacterial modulation, E. cloacae

\author{
*Corresponding author: \\ Sartini \\ Faculty of Pharmacy \\ Jl. Perintis Kemerdekaan km. 10, Tamalanrea, Makassar, South Sulawesi, Indonesia \\ Email: sardj@farmasi.unhas.ac.id
}




\section{INTRODUCTION}

In the last decade, many Enterobacter cloacae complex (ECC) that were initially classified as opportunistic have been regarded as infectious-causing bacteria in hospitals and turned out to be resistant to conventional or even newer generations of antibiotics (Annavajhala et al., 2019). Enterobacter cloacae, one of the Enterobacteriaceae species, is frequently isolated from patient specimens taken from the blood and the respiratory-, urinary-, and digestive tracts (Mezzatesta et al., 2012; Davin-Regli and Pagès, 2015). In addition, this pathogen has also been reported to contaminate medical equipment in hospitals (Davin-Regli and Pagès, 2015). Clinical isolates of $E$. cloacae were previously reported to be resistant against carbapenem, tigecycline, colistin (Huang et al., 2017). It was found that out of 385 patient specimens, $64.68 \%$ were found to be positive for pathogenic bacteria, including E. cloacae (2\%). Unfortunately, third-generation cephalosporins were also inefficient against most of these bacteria (Radji et al., 2011).

Researchers are trying to find appropriate solutions in response to the increased cases of infection by antibiotic-resistant bacteria, the scarcity of effective antibiotics, and the high cost required to discover new antibiotics (Towse et al., 2017). One of the suggested ways is by maintaining the use of existing antibiotics in combination with bioactive compounds from medicinal plants that could further improve the antibacterial activity of those antibiotics (Coutinho et al., 2008; Matias et al., 2011). It has been recently reported that certain phenolic compounds can increase the antibacterial activity of conventional antibiotics (Sartini et al., 2019). For example, the MICs of kanamycin, gentamycin, amikacin, neomycin were decreased as much as $87.5 \%$ or even 99.9\% when they were used in combination with the flavonoid-rich ethanolic extract of Croton campestris leaves (Júnior et al., 2011).

One of the natural resources demonstrated to incite antimicrobial activity against some pathogenic bacteria is green tea (Sartini et al., 2019). The antibacterial properties of green tea are mainly attributed to the catechin and caffeine compounds (Scoparo et al., 2012; Bermejo et al., 2015). In fact, epigallocatechin gallate (EGCG), a major catechin present in the green tea, was reported to increase gentamycin activity against multi-drug resistant (MDR) Escherichia coli (Parvez et al., 2019). However, it is essential to note that the combination of caffeine with several antibiotics yielded no improvement or even antagonistic activity towards some pathogenic bacteria (Bazzaz et al., 2016). Therefore, it is essential to note that the clinical combination of certain bioactive plant compounds and the existing antibiotics does not always improve the corresponding antibiotics' antibacterial activity. This research was carried out aiming to investigate whether green tea extract (GTE) could yield antibacterial activity and/or to improve the antibacterial activity of several $\beta$-lactam antibiotics (amoxicillin, cefotaxime, and imipenem) against clinical isolates of $E$. cloacae. Once it is proven, the use of existing $\beta$-lactam antibiotics can be further explored, in combination with certain bioactive compounds or plant extracts, for the clinical management of antibiotic-resistant pathogenic bacteria.

\section{MATERIALS AND METHOD \\ Materials}

Green tea used in this study was one of the commercial products marketed in Makassar, South Sulawesi, Indonesia. All antibiotic preparations and gallic acid were procured from SigmaAldrich. The Vitek ${ }^{\circledR} 2$ AST-G07 cassette (bioMe'rieux, Durham, NC), Brain Heart Infusion Broth (Merck), Muller Hinton Agar (Merck), and clinical isolates of E. cloacae were obtained from the Clinical Pathology Laboratory of Wahidin Sudiro Husodo Hospital in Makassar.

\section{Preparation of green tea ethanol extract}

Green tea ethanolic extract, or referred to as green tea extract (GTE), was prepared based on the previously established method (Sartini et al., 2019) with slight modifications. Briefly, GTE was prepared by firstly extracting the coarse powder of green tea by ultrasound-assisted maceration 
method for 15 minutes using hexane $(1: 10)$ to eliminate non-polar compounds. The resulting extract was subsequently subjected to ultra-sonication-assisted maceration using $50 \%$ ethanol with ratio of 1:10 for 15 minutes, and the resulting liquid GTE was kept at room temperature for $1 \times 24$ hours. At the designated time, the liquid GTE was processed using rotary evaporator at $60{ }^{\circ} \mathrm{C}$ and freeze dried to eliminate the water residue.

\section{Calculation of total phenolic content and epigallocatechin gallate content}

Total phenolic content (TPC) was confirmed and calculated by Folin-Ciocalteu spectrophotometry method based on the established protocol (Sartini et al., 2020), with slight modifications. Briefly, $10 \mathrm{mg}$ of GTE was dissolved in methanol to obtain GTE concentrations of $600,300,150$, and $75 \mu \mathrm{g} / \mathrm{mL}$, respectively. Afterward, $100 \mu \mathrm{L}$ of the obtained solution was immediately added to $2.5 \mathrm{~mL}$ of $7.5 \% \mathrm{w} / \mathrm{v}$ Folin-Ciocalteu reagent and homogenized. Following this step, $2.4 \mathrm{~mL}$ of $1 \% \mathrm{w} / \mathrm{v} \mathrm{NaOH}$ was subsequently added to the mixture. The reaction was maintained at ambient temperature for 60 minutes, and the resulting absorbance was determined using UV spectrophotometer -1800 (Shimadzu). Gallic acid was used as the standard solution.

Next, the amount of epigallocatechin gallate (EGCG) in the GTE was determined using Ultra-Fast Liquid Chromatography (UFLC). Initially, serial dilutions of standard EGCG were prepared in methanol to obtain a calibration curve with concentrations ranged from $3.25 \mu \mathrm{g} / \mathrm{mL}$ to $200 \mu \mathrm{g} / \mathrm{mL}$. Afterward, $10 \mathrm{mg}$ of GTE was dissolved in methanol, and the resulting solution was injected into the UFLC to precisely quantify the EGCG concentration.

\section{Antibiotic susceptibility test}

Susceptibilities of clinical isolates of E. cloacae (codes 13/04 and 275B/06) to antibiotics were tested using both Vitek ${ }^{\circledR} 2$ automatic test and disk diffusion methods (Stone et al., 2007), with slight modifications. For the $\operatorname{Vitek}^{\circledR} 2$ automatic test, bacterial suspension was freshly prepared in $0.45 \%$ saline to achieve equal turbidity with $0.5 \mathrm{McFarland}$ standard of the Densi-Chek 2 system (bioMe'rieux, Durham, NC). Subsequently, an antibacterial susceptibility testing card (AST-GN07) was inoculated with the prepared bacterial suspension. Results obtained from Vitek ${ }^{\circledR} 2$ were interpreted categorically based on the Advanced Expert System when available. For disk diffusion assay, plates of sterile Mueller-Hinton Agar were inoculated with $10 \mu \mathrm{L}$ of bacterial suspension, by spread methods, equal to the turbidity of $0.5 \mathrm{McFarland}$ standard. Commercially available antibiotic disks were immediately placed on the Mueller-Hinton Agar and incubated at $37^{\circ} \mathrm{C}$ for $1 \times 24$ hours. Interpretations of disk diffusion tests were carried out for Enterobacteriaceae based on the CLSI guidance, and categorical interpretations (susceptible, intermediate, or resistant) were subsequently assigned. The production of extended-spectrum $\beta$-lactamases (ESBL) was investigated by the double-disc synergy test (DDST) method, using cefotaxime and ceftazidime, either alone or in combination with clavulanic acid according to the previous study (Khalaf et al., 2008).

\section{Determination of antibacterial and modulation assay of green tea extract (GTE)}

The MIC of GTE, amoxicillin, cefotaxime, imipenem, and their combination was carried out by using the checkerboard microdilution assay (Fankam et al., 2017; Parvez et al., 2019), with slight modifications. Briefly, two-fold serial dilutions of each sample were freshly prepared in the BHIB in 96-well microtiter plates. Then, the suspension of E. cloacae was inoculated to each well to achieve $10^{6} \mathrm{CFU} / \mathrm{mL}$ of final concentration. Sequentially, the microplates were incubated at $37^{\circ} \mathrm{C}$ for $1 \times 24$ hours, and the MIC was subsequently determined by adding $10 \mu \mathrm{L}$ solution of $0.1 \%$ triphenyl tetrazolium chloride (TTC) to each well prior to incubation at ambient temperature for 30 minutes. The lowest concentration of the tested samples with unobservable TTC reduction to red formazan after a 30 -minute incubation at $37^{\circ} \mathrm{C}$ was defined as the MIC value. In addition, the modulation factor of the GTE was calculated based on the ratio of the MIC for the antibiotic alone 
and the MIC of the antibiotics in the presence of GTE. Modulation factor $\geq 2$ was used as the cutoff value to indicate substantial effects of the corresponding sample(s) in the reduction of the antibiotic resistance profiles of the tested pathogens (Fankam et al., 2017).

\section{RESULTS AND DISCUSSION}

\section{Extraction yield, total phenolic, and EGCG contents}

Extraction processes used in this research were carried out based on the method described in established publications (Veillet et al., 2010; Sartini et al., 2020). A summary of extraction yield, TPC, and EGCG content calculated from the obtained GTE are shown in Table 1.

Table 1. Extraction yield (\%), total phenolic content (TPC), and EGCG content of green tea ethanolic extract

\begin{tabular}{ccc}
\hline Extraction Yield (\%) & TPC (\%) & EGCG (\%) \\
\hline 27.87 & $51.64+0.21$ & $37.95+5.17$ \\
\hline
\end{tabular}

As shown in Table 1, TPC obtained in this study was approximately doubled compared to the previous study results (Sartini et al., 2019). In addition, we also found that the GTE prepared in this study contained higher EGCG than our previous result (Sartini et al., 2019). While the true nature of such discrepancy remains unknown, we hypothesized that the high content of polyphenols in the extract obtained in this study is due to an additional pre-treatment in the extraction process. As described in the method section, we performed GTE extraction using hexane with ultrasoundassisted extraction (UAE) to remove the non-polar components from GTE prior to the final extraction procedure using 50\% ethanol. The mechanical effect of UAE accelerated the release of organic compounds that contained within the plant body by disrupting cell walls, enhancing mass transfer, and facilitating solvent access to the cell content (Pasrija and Anandharamakrishnan, 2015).

\section{Susceptibility profiles of $\boldsymbol{E}$. cloacae clinical isolates to $\beta$-lactam antibiotics}

Susceptibility profiles of $E$. cloacae clinical isolates were determined using disk diffusion (Table 2), Vitek ${ }^{\circledR} 2$ (Table 3), and DDST (Figure 1 and Table 4) methods. Based on the results obtained from the agar disk diffusion test (Table 1) and Vitek ${ }^{\circledR} 2$ rapid test (Table 2), it appears that the clinical isolates of E.cloacae code 13/04 were resistant to the penicillin derivative (amoxicillinclavulanate) and sensitive to other antibiotics used in the assay: the cephalosporins (cefotaxime, ceftazidime, ceftriaxone) and the carbapenems (imipenem, meropenem, doripenem). However, the susceptibility profile of $E$. cloacae clinical isolate code $275 \mathrm{~B} / 06$ was quite different from the 13/04. While the 275B/06 E. cloacae were still sensitive to the carbapenems (imipenem, meropenem, and doripenem), this clinical isolate appeared to be resistant to the penicillin derivative (amoxicillinclavulanate) and the cephalosphorins (cefotaxime, ceftazidime, cefazoline, cefoxitin). Our results suggest that the two clinical isolates of E. cloacae might have different profiles in the availability of antibiotic resistance genes encoded in either the plasmid or the chromosome. 
Table 2. Susceptibility patterns of $E$. cloacae clinical isolates to $\beta$-lactam antibiotics by disk diffusion method

\begin{tabular}{|c|c|c|c|c|c|c|}
\hline \multirow{3}{*}{$\begin{array}{c}\text { E. cloacae } \\
\text { isolates }\end{array}$} & \multicolumn{6}{|c|}{ Inhibition zone diameter (mm) } \\
\hline & \multirow{2}{*}{$\begin{array}{c}\text { Penicillin } \\
\text { AMC }\end{array}$} & \multicolumn{3}{|c|}{ Cephalosporines } & \multicolumn{2}{|c|}{ Carbapenems } \\
\hline & & CAZ & CRO & CTX & IMI & MEM \\
\hline $13 / 04$ & $8 \mathrm{R}$ & $31 \mathrm{~S}$ & $33 \mathrm{~S}$ & $34 \mathrm{~S}$ & $29 \mathrm{~S}$ & $27 \mathrm{~S}$ \\
\hline $275 \mathrm{~B} / 06$ & $\mathrm{R}$ & $17 \mathrm{R}$ & $8 \mathrm{R}$ & $8 \mathrm{R}$ & $27 \mathrm{~S}$ & $25 \mathrm{~S}$ \\
\hline
\end{tabular}

Note: AMC: amoxicillin-clavulanate (20/10 $\mu \mathrm{g})$; CAZ: ceftazidime (30 $\mu \mathrm{g})$; CTX: cefotaxime (30 $\mu \mathrm{g})$; CRO: cefriaxone (30 $\mu \mathrm{g})$; IMI: imipenem (10 $\mu \mathrm{g})$; MEM: meropenem (10 $\mu \mathrm{g}) ; \mathrm{S}$ : sensitive, I: intermediate, R: resistant

Table 3. Susceptibility patterns of $E$. cloacae clinical isolates to $\beta$-lactam antibiotics by Vitek $^{\circledR} 2$ rapid test method

\begin{tabular}{cccccccc}
\hline \multirow{2}{*}{$\begin{array}{c}\text { E. cloacae } \\
\text { isolates }\end{array}$} & \multicolumn{3}{c}{$\begin{array}{c}\text { Antibiotics MIC (ppm) determined by Vitek-2 rapid test assay } \\
\text { Carbapenem }\end{array}$} \\
\cline { 2 - 8 } & Penicillin & \multicolumn{4}{c}{ Cephalosporines } & \multicolumn{4}{c}{ CMC } & CAZ & CTX & CRO & IMI & MEM & DORI \\
\hline $13 / 04$ & $>32 \mathrm{R}$ & $<1 \mathrm{~S}$ & $<1 \mathrm{~S}$ & $<1 \mathrm{~S}$ & $<0.25 \mathrm{~S}$ & $<0.25 \mathrm{~S}$ & $<0.12 \mathrm{~S}$ \\
$275 \mathrm{~B} / 06$ & $>32 \mathrm{R}$ & $>64 \mathrm{R}$ & $>64 \mathrm{R}$ & $>64 \mathrm{R}$ & $0.5 \mathrm{~S}$ & $<0.25 \mathrm{~S}$ & $<0.12 \mathrm{~S}$ \\
\hline
\end{tabular}

Note: AMC: amoxicillin-clavulanate; CAZ: ceftazidime; CTX: cefotaxim; CRO: ceftriaxone; IMI: imipenem; MEM: meropenem; DORI: doripenem; S: sensitive, I: intermediate, R: resistant

Further analysis using the DDST method revealed that the 276B/06 isolate was an extendedspectrum $\beta$-lactamase (ESBL) E. cloacae, while the 13/04 isolate was not (Figure 1 and Table 4). This is because the inhibitory zone diameter of cefotaxime-clavulanate was more than $5 \mathrm{~mm}$ compared to the result shown by cefotaxime alone. Since many bacteria in the Gram-negative Enterobacteriaceae family have been shown to be ESBL-producers (Rodríguez-Baño et al., 2018), our DDST result was already anticipated. Moreover, the same report (Rodríguez-Baño et al., 2018) suggested that the profile of clinically resistant E. cloacae was achieved not only by producing ESBL alone but may also involve the production of AmpC $\beta$-lactamase. This remains an interesting event to be explored in future experiments.

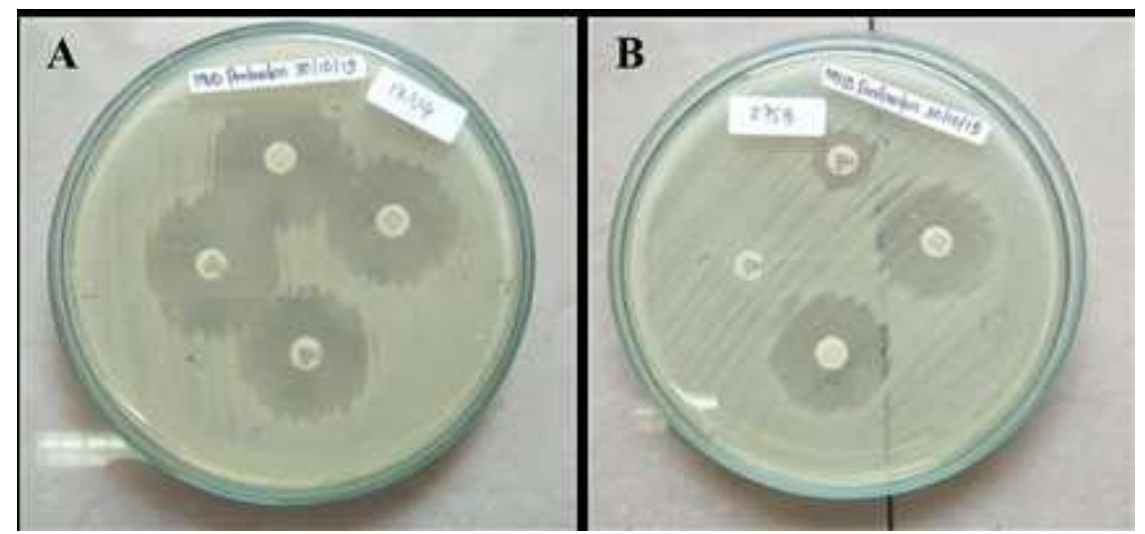

Figure 1. Susceptibility profiles of $\boldsymbol{E}$. cloacae clinical isolates to cefotaxime, ceftazidime, cefotaximeclavulanate, and ceftazidime-clavulanate by DDST method. A. E. cloacae code 13/04 (ESBL negative) B. E. cloacae code 275B/06 (ESBL positive) 
Table 4. Inhibition zone diameter $(\mathrm{mm})$ of several antibiotics against $E$. cloacae clinical isolates

\begin{tabular}{cccccc}
\hline $\begin{array}{c}\text { E. cloacae } \\
\text { isolates }\end{array}$ & $\begin{array}{c}\text { Ceftazidim - } \\
\text { clavulanate }\end{array}$ & Ceftazidim & $\begin{array}{c}\text { Cefotaxim - } \\
\text { clavulanate }\end{array}$ & Cefotaxim & Interpretation \\
\hline $13 / 04$ & 26 & 25 & 28 & 28 & ESBL Negative \\
$275 \mathrm{~B} / 06$ & 24 & 12 & 24 & 8 & ESBL Positive \\
\hline
\end{tabular}

Note: ESBL: extended-spectrum $\beta$-lactamase

\section{Minimum inhibitory concentration of $\beta$-Lactam antibiotics and/or GTE against $E$. cloacae clinical isolates}

To determine the antibacterial activity of $\beta$-lactam antibiotics or GTE in a single form or combination, we performed a checkerboard broth microdilution assay. This method has been suggested as one of the proper methods in determining the synergetic effect of two antibacterial or antibiotics used in combination (Jain et al., 2011; El-Azizi, 2016). As shown in Figure 2 and Table 5, the MIC of GTE against both E. cloacae clinical isolates (13/04 and 275B/06) were higher than $8,000 \mathrm{ppm}$, suggesting that the antibacterial activity of GTE is ineffective to both $\beta$-lactamsensitive (13/04) and $\beta$-lactam-resistant (275B/06) E. cloacae. In other words, the absence of GTE antibacterial activity observed in this study was not due to the resistance profile of $E$. cloacae. The reason for such results remains to be determined in the future.

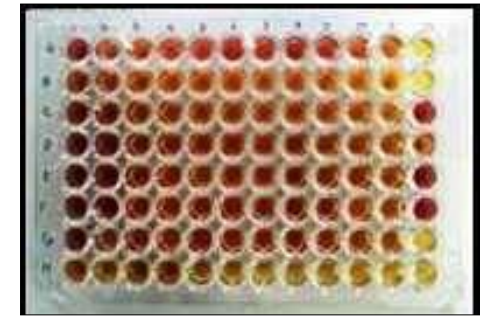

A

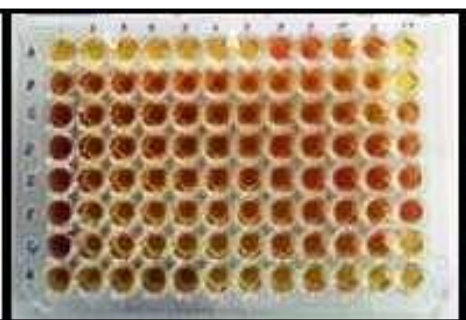

B

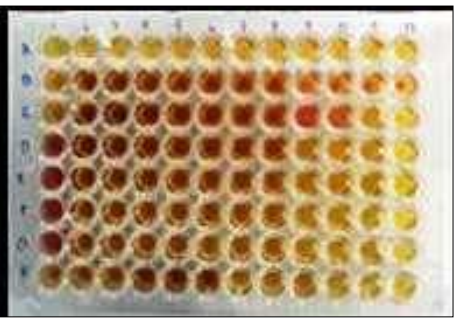

C

Figure 2. Checkerboard broth microdilution assay for antibiotics and/or GTE against $E$. cloacae clinical isolates

Notes: The sample test using two-fold dilution. A. Amoxicillin (2000 - 2 ppm); B. Cefotaxime (8000 - 8 ppm); C. Imipenem (250 - 0,25 ppm).

Antibiotics (Row A1-A11); GTE (column 1/ B1-F1); Antibiotic + GTE combination (Row B2-G11). Row H (control media + bacteria; control media); Column 12 (control media + GTE).

Red color in the media denotes bacterial growth, yellow color in the media indicates no bacterial growth

Table 5. Minimum inhibitory concentration (MICs) of amoxicillin, cefotaxime, imipenem, green tea extract (GTE), and combination of antibiotics with sub-inhibitory GTE against $E$. cloacae clinical isolates

\begin{tabular}{|c|c|c|}
\hline \multirow{2}{*}{ Test Samples } & \multicolumn{2}{|c|}{ MIC (ppm) } \\
\hline & E. cloacae $13 / 04$ & E. cloacae $275 \mathrm{~B} / 06$ \\
\hline Amoxicillin & $>2,000$ & $>2,000$ \\
\hline Cefotaxime & 125 & $>8,000$ \\
\hline Imipenem & 7.5 & 15 \\
\hline GTE & $>8,000$ & $>8,000$ \\
\hline Amoxicillin + sub inhibitory GTE & $>2,000$ & $>2,000$ \\
\hline Cefotaxime + sub inhibitory GTE & 125 & $>8,000$ \\
\hline Imipenem + sub inhibitory GTE & 0.2 & 7.5 \\
\hline
\end{tabular}

Note: concentration of sub-inhibitory GTE used in the assay was $8,000 \mathrm{ppm}$ 
Figure $2(\mathrm{~B} 1-\mathrm{F} 1)$ and Table 5 show that the ethanolic extract of green tea up to a concentration of $8 \%(8000 \mathrm{ppm})$ has not shown antibacterial activity against E.cloacae, which means that GTE is not effective as an antibacterial against E.cloacae. In the previous report, GTE was reported to constrain Escherichia coli with MIC value < 4000 ppm (Reygaert, 2014). We previously reported that GTE could impede Staphylococcus aureus growth at a concentration of $300 \mathrm{ppm}$ (Sartini et al., 2019). This is in line with the notion that the antimicrobial properties of green tea catechins are effective, to a greater extent, to Gram-positive bacteria than the Gramnegative ones (Reygaert, 2014). EGCG, the major catechin of green tea, has been considered a promising component in the GTE responsible for GTE's broad antibacterial activity against some Gram-negative and Gram-positive bacteria. This catechin can inhibit bacterial growth by several mechanisms, i.e., inhibition of bacterial cell wall synthesis, impairment of fatty acid synthesis, and inhibition of important enzymatic activities (Nakayama et al., 2013; Reygaert, 2014; Miklasińska et al., 2016).

From Table 5, it can be seen that the combination of antibiotics with GTE did not change the MIC values of amoxicillin and cefotaxime on the clinical isolates of E. cloacae tested in this study, suggesting that GTE did not augment the antibacterial activity of the corresponding antibiotics. However, it is essential to note that the antibacterial activities of imipenem against the non-ESBL E. cloacae (code 13/04) and the ESBL strain of E. cloacae (code 275B/06) were increased by forty-fold and two-fold, respectively. Our results were in line with the previous research results that demonstrated the enhanced bactericidal activity of imipenem against imipenem resistant-Klebsiella pneumonia in the presence of EGCG, a major component of GTE (Cho et al., 2011)

\section{CONCLUSION}

Green tea ethanolic extract (GTE) was able to augment the antibacterial activity of imipenem against both the non-ESBL and the ESBL isolates of E. cloacae. However, it did not provide any beneficial effect on the antibacterial activities of amoxicillin and cefotaxime.

\section{ACKNOWLEDGEMENT}

Authors would like to offer our gratitude to the Ministry of Research, Technology and Higher Education, the Republic of Indonesia, for the funding support in the form of Hibah Magister's research grant with contract no. 2759/UN/421/KU0201/2019.

\section{REFERENCES}

Annavajhala, M.K., Gomez-Simmonds, A., and Uhlemann, A.-C. (2019). Multidrug-resistant Enterobacter cloacae complex emerging as a global, diversifying threat. Frontiers in Microbiology 10(44),1-8. https://doi.org/10.3389/fmicb.2019.00044

Bazzaz, B.S.F., Sarabandi, S., Khameneh, B., and Hosseinzadeh, H. (2016). Effect of catechins, green tea extract and methylxanthines in combination with gentamicin against Staphylococcus aureus and Pseudomonas aeruginosa: - combination therapy against resistant bacteria. Journal of Pharmacopuncture 19(4), 312-318. doi: 10.3831/KPI.2016.19.032

Bermejo, D.V., Mendiola, J.A., Ibáñez, E., Reglero, G., and Fornari, T. (2015). Pressurized liquid extraction of caffeine and catechins from green tea leaves using ethyl lactate, water and ethyl lactate + water mixtures. Food and Bioproducts Processing 96, 106-112. doi: https://doi.org/10.1016/j.fbp.2015.07.008

Cho, Y.S., Oh, J.J., and Oh, K.H. (2011). Synergistic anti-bacterial and proteomic effects of epigallocatechin gallate on clinical isolates of imipenem-resistant Klebsiella pneumoniae. Phytomedicine 18(11), 941-946. doi: 10.1016/j.phymed.2011.03.012 
Coutinho, H.D., Costa, J.G., Lima, E.O., Falcão-Silva, V.S., and Siqueira-Júnior, J.P. (2008). Enhancement of the antibiotic activity against a multiresistant Escherichia coli by Mentha arvensis L. and chlorpromazine. Chemotherapy 54(4), 328-330. https://doi.org/10.1159/000151267

Davin-Regli, A., and Pagès, J.-M. (2015). Enterobacter aerogenes and Enterobacter cloacae; versatile bacterial pathogens confronting antibiotic treatment. Frontiers in Microbiology 6, 392-392. https://doi.org/10.3389/fmicb.2015.00392

El-Azizi, M. (2016),Novel microdilution method to assess double and triple antibiotic combination therapy in vitro. International Journal of Microbiology, Volume 2016, Article ID 4612021,1-10

Fankam, A.G., Kuiate, J.-R., and Kuete, V. (2017). Antibacterial and antibiotic resistance modulatory activities of leaves and bark extracts of Recinodindron heudelotii (Euphorbiaceae) against multidrug-resistant Gram-negative bacteria. BMC Complementary And Alternative Medicine 17(1), 168-168. https://doi.org/10.1186/s12906-017-1687-2

Huang, L.F., Lee, C.T., Su, L.H., and Chang, C.L. (2017). A Snapshot of co-resistance to carbapenems and tigecycline in clinical isolates of Enterobacter cloacae. Microb Drug Resist 23(1), 1-7. doi: 10.1089/mdr.2015.0311

Jain, S., T, V., V, R., Bc, D., Sampath, A., Siddhalingeshwar, et al. (2011). Antibiotic synergy test: Checkerboard method on multi drug resistant Pseudomonas aeruginosa. International Research Journal of Pharmacy 2, 196-198

Júnior, F., Matias, E., Oliveira, D., Ramos, A., Fernandes, C., Souza, H., et al. (2011). Modulatory antibiotic activity and chemical composition of hydroalcoholic extract of Croton campestris. Journal of Medicinal Plant Research 5(18), 4400-4404

Khalaf, N., Shakya, A., Al-Othman, A., Elagbar, Z., and Farah, H. (2008). Antioxidant activity of some common plants. Turkish Journal of Biology, 32, 51-55

Matias, E.F.F., Santos, K.K.A., Almeida, T.S., Costa, J.G.M., and Coutinho, H.D.M. (2011). Phytochemical screening and modulation of antibiotic activity by Ocimum gratissimum L. Biomedicine \& Preventive Nutrition 1(1), 57-60. doi: https://doi.org/10.1016/j.bionut.2010.09.007

Mezzatesta, M.L., Gona, F., and Stefani, S. (2012). Enterobacter cloacae complex: clinical impact and emerging antibiotic resistance. Future Microbiol 7(7), 887-902. doi: 10.2217/fmb.12.61

Miklasińska, M., Kępa, M., Wojtyczka, R.D., Idzik, D., Dziedzic, A., and Wąsik, T.J. (2016). Catechin hydrate augments the antibacterial action of selected antibiotics against Staphylococcus aureus clinical strains. Molecules (Basel, Switzerland) 21(2), 244-244. https://doi.org/10.3390/molecules21020244

Nakayama, M., Shimatani, K., Ozawa, T., Shigemune, N., Tsugukuni, T., Tomiyama, D., et al. (2013). A study of the antibacterial mechanism of catechins: Isolation and identification of Escherichia coli cell surface proteins that interact with epigallocatechin gallate. Food Control 33(2), 433-439. https://doi.org/10.1016/j.foodcont.2013.03.016

Parvez, M., Saha, K., Rahman, J., Munmun, A., Rahman, A., Dey, D.S., et al. (2019). Antibacterial activities of green tea crude extracts and synergistic effects of epigallocatechingallate (EGCG) with gentamicin against MDR pathogens. Heliyon 5(7), 1-5, https://doi.org/10.1016/j.heliyon.2019.e02126

Pasrija, D., and Anandharamakrishnan, C. (2015). Techniques for extraction of green tea polyphenols: A review. Food and Bioprocess Technology 8(5), 935-950. doi: 10.1007/s11947-015-1479-y

Radji, M., Fauziah, S., and Aribinuko, N. (2011). Antibiotic sensitivity pattern of bacterial pathogens in the intensive care unit of Fatmawati Hospital, Indonesia. Asian Pacific Journal of Tropical Biomedicine 1(1), 39-42. https://doi.org/10.1016/S2221-1691(11)60065-8 
Reygaert, W.C. (2014). The antimicrobial possibilities of green tea. Frontiers In Microbiology 5, 434-434. https://doi.org/10.3389/fmicb.2014.00434

Rodríguez-Baño, J., Gutiérrez-Gutiérrez, B., Machuca, I., and Pascual, A. (2018). Treatment of infections caused by extended-spectrum-beta-lactamase-, ampc-, and carbapenemaseproducing Enterobacteriaceae. Clinical Microbiology Reviews 31(2), e00079-00017. doi: 10.1128/CMR.00079-17

Sartini, S., Djide, M., Amir, M., and Permana, A. (2020). Phenolic-rich green tea extract increases the antibacterial activity of amoxicillin against Staphylococcus aureus by in vitro and ex vivo studies. Journal of Pharmacy and Pharmacognosy Research 8(6), 491-500

Sartini, S., Djide, M.N., and Nainu, F. (2019). Correlation phenolic concentration to antioxidant and antibacterial activities of several ethanolic extracts from Indonesia. Journal of Physics: Conference Series 1341, 072009,1-9. doi: 10.1088/1742-6596/1341/7/072009

Scoparo, C.T., de Souza, L.M., Dartora, N., Sassaki, G.L., Gorin, P.A., and Iacomini, M. (2012). Analysis of Camellia sinensis green and black teas via ultra high performance liquid chromatography assisted by liquid-liquid partition and two-dimensional liquid chromatography (size exclusion $\times$ reversed phase). J Chromatogr A 1222, 29-37. doi: 10.1016/j.chroma.2011.11.038

Stone, N.D., O'Hara, C.M., Williams, P.P., McGowan, J.E., Jr., and Tenover, F.C. (2007). Comparison of disk diffusion, VITEK 2, and broth microdilution antimicrobial susceptibility test results for unusual species of Enterobacteriaceae. Journal Of Clinical Microbiology 45(2), 340-346. doi: 10.1128/JCM.01782-06

Towse, A., Hoyle, C.K., Goodall, J., Hirsch, M., Mestre-Ferrandiz, J., and Rex, J.H. (2017). Time for a change in how new antibiotics are reimbursed: Development of an insurance framework for funding new antibiotics based on a policy of risk mitigation. Health Policy 121(10), 1025-1030. doi: 10.1016/j.healthpol.2017.07.011

Veillet, S., Tomao, V., and Chemat, F. (2010). Ultrasound assisted maceration: An original procedure for direct aromatisation of olive oil with basil. Food Chemistry 123(3), 905-911. doi: https://doi.org/10.1016/j.foodchem.2010.05.005 
